\title{
О ВЛИЯНИИ ВОЛН ТРОПИЧЕСКОЙ НЕУСТОЙЧИВОСТИ НА СОБЫТИЯ ЭЛЬ-НИНЬО И ЛА-НИНЬЯ
}

\author{
Серых И.В.
}

\author{
Институт океанологии им. П.П. Ширшова РАН, 117997, г. Москва, \\ Нахимовский проспект, д. 36, тел.+7916 114-0969, e-mail: iserykh@ocean.ru
}

\begin{abstract}
According to satellite observations and buoy stations, changes in temperature and currents in the tropics of the Pacific Ocean were investigated. It is shown that the sea surface temperature anomalies characteristic for the El Niño and La Niña events are due to the equatorial upwelling caused by tropical instability waves.
\end{abstract}

Температура поверхности центрально-восточной части экваториальной зоны Тихого океана (ТПО) в среднем составляет $24-26^{\circ} \mathrm{C}$ и холоднее вод, расположенных севернее этого региона, средняя температура которых равна $27-28^{\circ} \mathrm{C}$. Иногда в Тихом океане возникают условия, когда аномалии экваториальной ТПО в центре и на востоке увеличиваются в среднем на $1-2^{\circ} \mathrm{C}$. Такое явление обычно продолжается около года и получило название Эль-Ниньо (рис. 1). Часто возникают условия, когда аномалии ТПО центрально-восточной экваториальной зоны уменьшаются в среднем на $0.5-1.5^{\circ} \mathrm{C}$, такое состояние Тихого океана называется Ла-Нинья (рис. 2). Фактически Эль-Ниньо и Ла-Нинья это крайние состояния одного явления - Эль-Ниньо - Южного колебания, где Южное колебание представляет собой разность атмосферного давления на уровне моря между г. Дарвин (Австралия) и о. Таити [1].

В представленной работе по данным буйковых станций программы TOGA-TAO исследованы изменения температуры и течений в тропиках Тихого океана на различных глубинах. Также исследованы данные спутниковых наблюдений AVISO за аномалиями уровня моря (АУМ) за 1993-2016 гг., и ТПО из NOAA OISST V2 за 1982-2017 гг. Дополнительно анализировались результаты усвоения океанических данных JPL ECCO и ре-анализа $1 / 32^{\circ}$ NLOM. Для обработки данных использован разработанный в ИО РАН «Программный комплекс для пространственно-временного анализа глобальных вековых полей гидрометеорологических характеристик». 
Анализ данных показал, что изменения ТПО в центральной части экваториальной зоны Тихого океана обусловлены экваториальным апвеллингом, вызванным долгопериодными волнами, получившими название волны тропической неустойчивости (ВТН). ВТН распространяются с востока на запад вдоль экватора с фазовой скоростью около $50 \mathrm{~cm} / \mathrm{c}$, имеют период 17-30 суток, длину волны приблизительно 1000-1100 км и обладают помимо волновых еще и вихревыми свойствами. ВТН выстраиваются в группы, модулируют с периодом близким к одному году, и их модуляции имеют постоянную фазу. Была получена тесная связь параметров этих волн и экваториальной температуры верхнего слоя Тихого океана, являющейся основной характеристикой состояния явления Эль-Ниньо - Ла-Нинья [2]. Так во время Эль-Ниньо наблюдается затухание ВТН, в следствии чего ослабевает экваториальный апвеллинг и происходит аномально сильный нагрев Солнцем приповерхностного слоя океана в этом регионе (рис. 1). Во время Ла-Нинья происходит усиление ВТН, что вызывает подъем холодных вод на поверхность у экватора, и, как следствие, отрицательные аномалии ТПО (рис. 2).
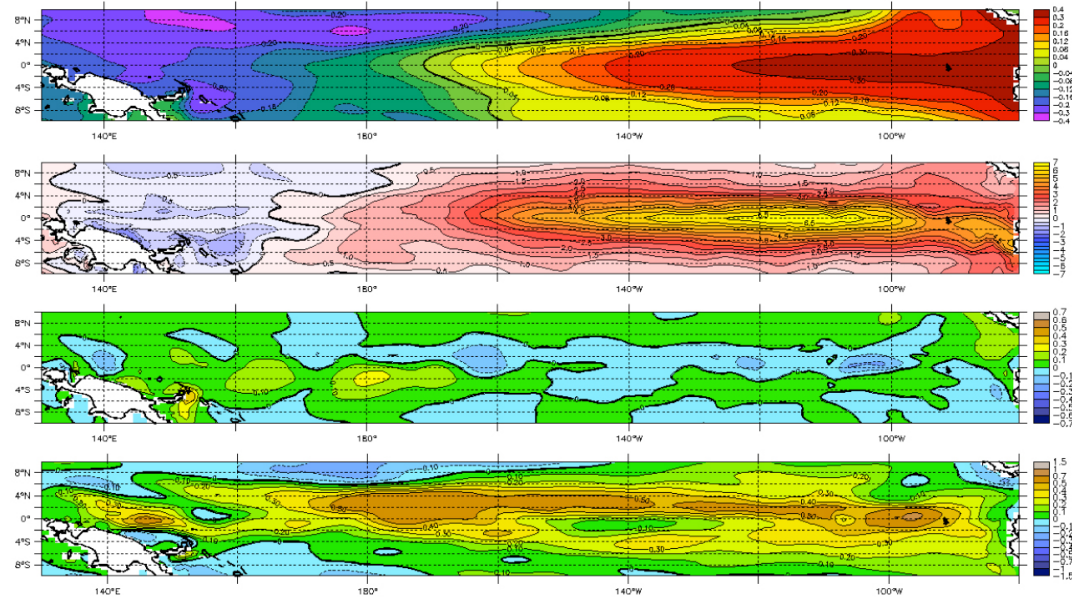

Рис. 1. Аномалии (сверху вниз) уровня поверхности океана (м), температуры воды на глубине 15 м $\left({ }^{\circ} \mathrm{C}\right)$, меридиональной (с юга на север) скорости течений на глубине 15 м (м/сек), зональной (с запада на восток) скорости течений на глубине 15 м (м/сек) во время события Эль-Ниньо (1997.11.30).

В период Эль-Ниньо ВТН затухают из-за уменьшения скоростей течений и температурного градиента между водами Южно-пассатного 

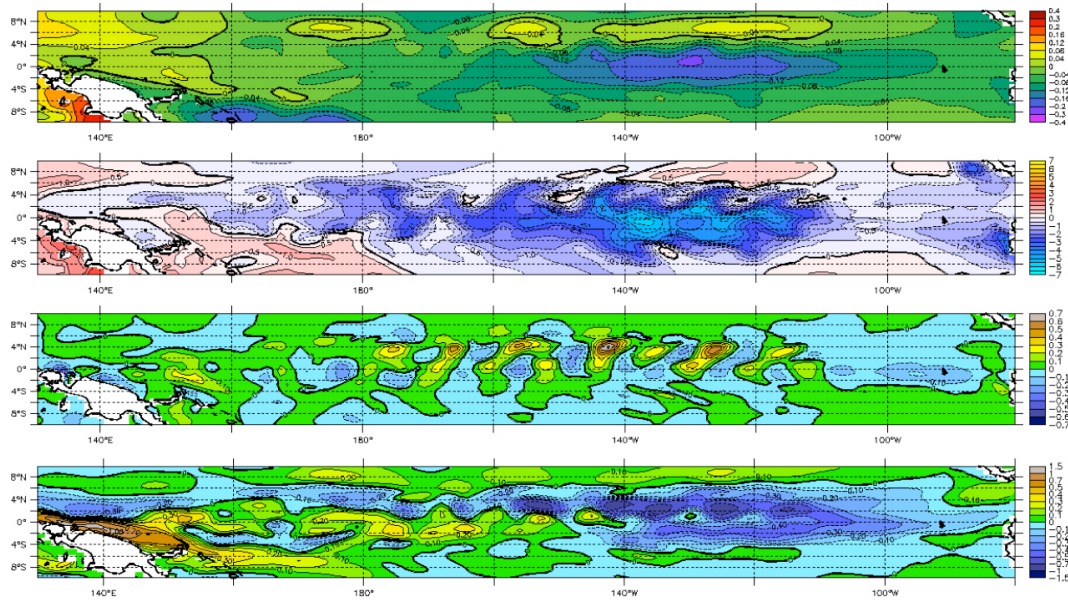

Рис. 2. То же самое, что и на рис. 1, но во время события Ла-Нинья (1998.11.30).

течения и более теплыми водами Экваториального противотечения, вызванного переносом волнами Кельвина положительных аномалий ТПО из западной части Тихого океана, а также ослаблением пассатов, холодного Перуанского течения и апвеллинга у берегов Эквадора. Усиление же ВТН в период Ла-Нинья происходит из-за усиления пассатов, увеличения скоростей Южного-пассатного течения, Экваториального противотечения и холодного подповерхностного противотечения Кромвеля. Таким образом срабатывают обратные положительные связи, приводящие к развитию Эль-Ниньо и Ла-Нинья.

Используя спутниковые данные АУМ и аномалий ТПО обнаружено существование подобных структур на экваторе не только в Тихом, но и в Атлантическом и Индийском океанах, в которых существуют свои аналоги Эль-Ниньо, связанные с тропиками Тихого океана атмосферными ячейками циркуляции Уокера $[3,4]$.

Описана гипотетическая схема возбуждения Эль-Ниньо северотихоокеанским полюсным приливом, который сам возбуждается 14-месячным чандлеровским колебанием полюсов Земли и распространяется с запада на восток в умеренных широтах $[5,6]$. Достигнув берегов Северной Америки, этот прилив трансформируется в прибой, и волна этого прибоя движется к Панамскому перешейку. В сочетании с одновременным усилением северо-восточных пассатов, которое происходит при осеннем смещении к югу зоны внутритропической конвергенции, эта прибойная волна возбуждает там положительные аномалии ТПО, 
характерные для Эль-Ниньо. В АУМ и аномалиях ТПО дальнейшее продвижение приливной волны прослеживается в западном направлении вплоть до берегов Индонезийского архипелага. При этом обнаруживается, что от движущейся прибойной волны поочередно отрываются и уходят к северу и югу вторичные волны. Эти волны способны воздействовать на ВТН и экваториальный апвеллинг, что важно для развития процессов событий Эль-Ниньо и Ла-Нинья.

Таким образом Эль-Ниньо зависит от нескольких внешних сил: годового хода притока тепла от Солнца и чандлеровского колебания полюсов Земли, периоды которых, по-видимому, несоизмеримы друг с другом. Что является проявлением так называемого странного нехаотического аттрактора (CHA). Из этого следует принципиальная возможность долгосрочных (на годы вперед) предсказаний Эль-Ниньо.

Исследование выполнено при финансовой поддержке по гранту Российского научного фонда (проект №14-50-00095).

\section{ЛИТЕРАТУРА}

1. Федоров К.Н. Этот капризный младенец - Эль-Ниньо! // Природа. 1984. № 8. C. $65-74$.

2. Бондаренко А.Л., Серых И.В. О формировании явления Эль-Ниньо-ЛаНиньа Тихого океана // Современные проблемы дистанционного зондирования земли из космоса. 2011. Т. 8. № 2. С. 57-63.

3. Бышев В.И., Иванов Ю.А., Нейман В.Г., Романов Ю.А., Серых И.В., Скляров В.Е., Щербинин А.Д. О проявлении эффекта Эль-Ниньо в Индийском океане // Доклады Академии наук. 2008. Т. 418. № 3. С. 391-396.

4. Бышев В.И., Нейман В.Г., Романов Ю.А., Серых И.В. О влиянии событий Эль-Ниньо на климатические характеристики Индоокеанского региона // Океанология. 2012. Т. 52. № 2. С. 165-175.

5. Серых И.В., Сонечкин Д.М. О влиянии полюсного прилива на Эль-Ниньо // Современные проблемы дистанционного зондирования Земли из космоса. 2016. Т. 13. № 2. С. 44-52.

6. Серых И.В., Сонечкин Д.М. О проявлениях движений полюсов Земли в ритмах Эль-Ниньо - Южного колебания // Доклады Академии наук. 2017. T. 472. № 6. С. 716-719. 